\title{
Survei Kelayakan Sarana dan Prasarana pada 31 Cabang Olahraga Anggota KONI Kota Jambi Peserta Pekan Olahraga Provinsi Jambi Ke-23
}

\author{
Boy Indrayana, Ely Yuliawan \\ Fakultas Keguruan dan Ilmu Pendidikan, Universitas Jambi \\ Boy_indrayana@unja.ac.id,ellyuliawan.fik@unja.ac.id
}

\begin{abstract}
Abstrak: Latar belakang masalah dalam penelitian ini adalah sarana dan prasarana olahraga pada 31 cabang olahraga di Kota Jambi yang juga termasuk organisasi olahraga yang terdaftar di KONI Kota jambi. Penelitian ini bertujuan untuk mengetahui keberadaan, kondisi dan status kepemilikan sarana dan prasarana olahraga pada setiap cabang olahraga yang ada di Kota Jambi di tahun 2020. Penelitian ini adalah penelitian deskriptif dengan metode survei menggunakan instrumen lembar observasi. Populasi penelitian ini menggunakan subjek seluruh cabang olahraga di Kota Jambi sebanyak 31 cabang olahraga dengan objek sarana dan prasarana lapangan atau venue pertandingan. Teknik analisis data menggunakan teknik analisis dekriptif kuantitatif yang disajikan dalam bentuk klasifikasi jenis data persentase. Hasil penelitian menunjukkan bahwa sarana dan prasarana olahraga di Kota Jambi sebanyak 31 cabang olahraga yang ada di Kota jambi terdapat 42 sarana dan prasarana olahraga yang dapat digunakan dalam pelaksanaan Pekan Olahraga Provinsi yang ke 23 di Kota Jambi, 9 sarana dalam kategori baik sekali dengan persentase $21.4 \%$, 29 sarana dalam kategori baik dengan persentase $69 \%$, 4 sarana dalam kategori sedang dengan persentase $9.6 \%$ dan tidak ada sarana dalam kategori kurang.
\end{abstract}

Kata Kunci: Kelayakan, Sarana, Prasarana

\section{Feasibility Survey for Facilities and Infrastructure at 31 Sports Member of KONI in Jambi City Participants in the 23rd Jambi Province Sports Week}

\begin{abstract}
The problem in this research is sports facilities and infrastructure in 31 sports in Jambi City which also includes sports organizations registered in KONI Kota Jambi. This study aims to determine the existence, condition and status of ownership of sports facilities and infrastructure in each sport in Jambi City. This research is a descriptive study with a survey method using the observation sheet instrument. The population of this study used the subjects of all sports in Jambi City as many as 31 sports with the object of field facilities and infrastructure or match venues. The data analysis technique used quantitative descriptive analysis techniques which were presented in the form of classifying the types of percentage data.The results showed that there were as many as 31 sports facilities and infrastructure in Jambi City in Jambi City, there were 42 sports facilities and infrastructure that could be used in the 23rd Provincial Sports Week in Jambi City, 9 facilities were in the very good category with a percentage of 21. 4\%, 29 facilities were in the good category with a percentage of 69\%, 4 facilities were in the medium category with a percentage of $9.6 \%$ and no facilities were in the poor category.
\end{abstract}

Keywords: Feasibility, Facilities, Infrastructure 


\section{PENDAHULUAN}

Manusia sebagai mahluk yang memiliki bentuk fisik tentu sangat membutuhkan faktor penunjang demi mencapai bentuk fisik yang sempurna. Aspek fisik dari olahraga selalu dapat menarik masyarakat untuk melakukan kegiatan olahraga, meskipun demikian aspek rohani pun akan terlibat dalam suatu gerak karena kedua memang saling memiliki faktor yang tidak terpisahkan.

Keberadaan olahraga dalam masyarakat juga dapat memberikan makna terhadap kehidupan manusia serta dapat dijadikan media pendidikan. Kegiatan olahraga sendiri tidak lepas dari organisasi gerak yang dilakukan agar olahraga tersebut dapat berjalan dengan selaras dan mencapai tujuan yang diinginkan. Organisasi olahraga tersebut dapat berupa peraturan, ataupun teknik gerak. Organisasi olahraga sendiri tidak berhenti sampai disitu, sebuah perkumpulan dari kegiatankegiatan olahraga yang sama akan menghasilkan sebuah organisasi olahraga yang dapat mengatur, menyelenggarakan, atau mengembangkan sebuah kegiatan olahraga agar lebih dapat berguna bagi kehidupan masyarakat.

Kegiatan olahraga berkembang dengan berbagai bentuk dalam cara pelaksanaannya, pengorganisasian, dan tujuan yang berbeda-beda. Sehubungan dengan hal sesuai dalam UndangUndang Republik Indonesia No. 3 tahun 2005 pasal 1 ayat 11, 12, 13 tentang Sistem Keolahragaan Nasional menyebutkan olahraga dibagi menjadi beberapa bagian diantaranya, olahraga pendidikan, olahraga rekreasi, dan olahraga Prestasi. Olahraga pendidikan adalah pendidikan jasmani dan olahraga yang dilaksanakan sebagai bagian proses pendidikan yang teratur dan berkelanjutan untuk memperoleh pengetahuan, kepribadian, keterampilan, kesehatan dan kebugaran jasmani. Olahraga rekreasi adalah olahraga yang dilakukan oleh masyarakat dengan kegemaran dan kemampuan yang tumbuh dan berkemban sesuai dengan kondisi dan nilai budaya masyarakat setempat untuk kesehatan, kebugaran, dan kegembiraan. Olahraga prestasi adalah olahraga yang membina dan mengembangkan olahragawan secara terencana, berjenjang, dan berkelanjutan melalui kompetisi untuk mencapai prestasi dengan dukungan ilmu pengetahuan dan teknologi keolahragaan.

Di tingkat provinsi seperti dalam Pekan Olahraga Provinsi (PORPROV). Kegiatan olahraga merupakan bagian dari kegiatan sosial. Olahraga bukan semata-mata kegiatan individu. Olahraga dengan keberagamannya memiliki banyak jenis, yakni pendidikan, prestasi sampai pada rekreasi, namun dalah hal ini dibahas tentang olahraga yang mengacu pada kegiatan pertandingan, tentu hal ini memiliki kekuatan-kekuatan tertentu, yaitu kekuatan sosial. Kehebatan atlet dalam suatu cabang olahraga dapat mengangkat martabat suatu Negara dan juga dapat dipandang sebagai simbol keunggulan kelompok, masyarakat atau bangsa. Kegiatan olahraga diwadahi oleh berbagai organisasi, seperti olahraga pendidikan yang diorganisir oleh sekolah, olahraga rekreatif dan kesehatan yang diorganisir oleh klub-klub kesehatan masyarakat, dan organisasi olahraga prestasi yang diorganisir oleh induk-induk organisasi olahraga yang dikoordinir oleh Komite Olahraga Nasional Indonesia (KONI) merupakan lembaga yang mengelola pembinaan prestasi olahraga. Di masyarakat tersebar klub-klub berbagai cabang olahraga sebagai organisasi prestasi.

Dalam sebuah penyelengaaran event pastinya memerlukan suatu alat atau media, sehingga mempermudah dalam proses pelaksanaannya. Sarana dan prasarana yang dimaksutkan dalam olahraga adalah segala sesuatu media yang digunakan dalam kebutuhan berolahraga. Sarana dan prasarana dalam penyelenggaraan event harus tersedia di setiap cabang olahraga guna untuk mencapai tujuan dalam pencapaiannya.

Keberadaan sarana dan prasarana sangat mempengaruh cepat atau lambatnya terlaksanannya kegiatan. Persiapan yang kurang maksimal dan apabila tidak memiliki sarana dan prasarana yang memadai, mengingat hampir cabang olahraga memerlukan sarana dan prasarana yang beraneka ragam di khawatirkan penyelenggaran tersebut tidak akan berjalan lancar sebagaimana mestinya sesuai waktu yang ditentukan. Kebutuhan sarana dan prasarana plahraga setiap cabang olahraga adalah sangat vital artinya bahwa penyelenggaraan kegiatan harus menggunakan sarana dan prasarana yang sesuai dengan kebutuhan dan penggunaannya.

Di dalam Undang-Undang Republik Indonesia No. 3 tahun 2005 pasal 1 ayat 20 dan 21 tentang Sistem Keolahragaan Nasional menyebutkan Prasarana olahraga adalah tempat atau ruang termasuk lingkungan yang digunakan untuk kegiatan olahraga dan/atau penyelenggaraan 
keolahragaan. Sarana olahraga adalah peralatan dan perlengkapan yang digunakan untuk kegiatan olahraga.

Sarana olahraga adalah sumber daya pendukung yang terdiri dari segala bentuk dan jenis peralatan serta perlengkapan yang digunakan dalam kegiatan olah raga. Prasarana olah raga adalah sumber daya pendukung yang terdiri dari tempat olah raga dalam bentuk bangunan di atasnya dan batas fisik yang statusnya jelas dan memenuhi persyaratan yang ditetapkan untuk pelaksanaan program kegiatan olah raga. Sarana dan prasarana juga harus memenuhi syarat agar tercipta proses latihan secara efektif. Banyak cabang olahraga di kota jambi kurang memiliki sarana dan prasarana sebagai fasilitas atlet untuk melakukan gerak, yang dikarenakan sempitnya atau sudah padatnya lahan di perkotaan serta alokasi bantuan dana yang diberikan oleh pemerintah Kota. Hal tersebut merupakan kendala yang berarti bagi kelancaran proses pembinaan prestasi.

Kebanyakan kendala cabang olahraga yang berada di Kota Jambi adalah sarana olahraga yang kurang lengkap. Akan tetapi fakta yang terjadi belum tentu seperti itu, bisa jadi sarana dan prasarana olahraga yang tidak standar atau memenuhi syarat yang ditentukan. Kurangnya sarana akan menghambat proses latihan pada atlet.Atlet akan mengantri dalam pergantian menggunakan peralatan sehingga atlet akan menjadi bosan dalam latihan. Ini akan mengakibatkan pembinaan tidak akan maksimal. Hal tersebut harus dihindari demi pembinaan dan peningkatan prestasi, maka sarana olahraga harus disesuaikan dengan kebutuhannya dan mengkondisikannya dengan baik agar pembinnaan dapat berjalan dengan lancar dan baik.

\section{METODE}

Penelitian tentang Survei Sarana dan Prasarana pada setiap Cabang Olahraga ini menggunakan penelitian deskriptif kuntitatif. Prosesnya berupa pengumpulan dan penyusunan data, serta analisis dan penafsiran data tersebut. Metode dalam penelitian ini adalah metode survei menggunakan angket dengan teknik menghitung sarana dan prasana olahraga yang ada di Kota Jambi. Dilakukan dengan metode survei agar dapat melihat secara langsung keadaan sarana dan prasarana olahraga di Kota Jambi.

Definisi operasional penelitian ini adalah jumlah keberadaan, kondisi dan kelayakan sarana dan prasarana olahraga sebagai penunjang tercapainya tujuan pembinaan atlet dan pelaksanaan event sehingga dapat terlaksana secara optimal sesuai dengan fungsinya. Keberadaan menjelaskan ada atau tidak ada dan berapa jumlah sarana dan prasarana olahraga, kondisi menjelaskan tentang berapa jumlah keadaan setiap sarana dan prasarana olahraga yang baik dan yang rusak, sedangkan status kepemilikan menjelaskan tentang berapa jumlah sarana dan prasarana pendidikan jasmani yang milik sendiri dan meminjam. Peneliti menggunakan lembar observasi untuk mencatat keadaan sarana dan prasarana olahraga di Kota Jambi.

Populasi dari penelitian ini adalah cabang olahraga se-Kota Jambi berjumlah 31 cabang olahraga ditahun 2020. Semua populasi dijadikan objek sehingga penelitian ini dapat dinyatakan sebagai penelitian populasi. Dalam penelitian ini metode yang digunakan adalah metode survei dengan menggunakan lembar observasi sebagai alat pengambilan data untuk mencatat hasil dari survei.

Teknik pengumpulan data dalam penelitian ini dilakukan secara observasi langsung, yaitu dengan melakukan pengamatan secara langsung terhadap sumber data/objek penelitian kemudian atas bantuan dari guru pendidikan jasmani peneliti melihat langsung dan mengisi data dilembar observasi baik yang ada di gudang maupun tempat lain sesuai dengan lembar observasi yang telah disusun.

Teknik analisis yang digunakan dalam penelitian ini adalah analisis deskriptif. Menurut Sugiyono (2006: 21) statistik deskriptif adalah statistik yang berfungsi untuk mendeskripsikan atau memberi gambaran terhadap objek yang diteliti melalui data sampel atau populasi sebagaimana adanya, tanpa melakukan analisis dan membuat yang berlaku untuk umum. Menurut Anas Sudijono (2007: 4) statistik deskriptif adalah statistik yang tingkat pekerjaannya mencakup cara menghimpun, menyusun, atau mengatur, mengolah, menyajikan dan 
menganalisis data angka agar dapat memberikan gambaran yang teratur, ringkas dan jelas mengenai gejala, peristiwa atau keadaan.

Analisis yang digunakan adalah deskriptif kuantitatif dengan cara mengklasifikasikan jenis data yang diperoleh dari lembar observasi. Data dikategorikan mengenai jumlah keberadaan, kondisi dan status kepemilikan sarana dan prasarana olahraga.

\section{HASIL DAN PEMBAHASAN}

Setelah dilakukan pengambilan data dan telah diperoleh hasil data di masing-masing sarana olahraga 31 cabang olahraga hasilnya berbeda-beda. Hasil penelitian dapat diketahui pada tabel 1 berikut:

Tabel 1 Jumlah Keberadaan Sarana olahraga.

\begin{tabular}{|c|c|c|}
\hline No & Nama Organisasi Cabang Olahraga & $\begin{array}{c}\text { Jumlah keberadaan Sarana } \\
\text { Olahraga }\end{array}$ \\
\hline 1 & PRSSI (Renang) & 3 \\
\hline 2 & PSSI (Sepak Bola) & 2 \\
\hline 3 & PTMSI (Tenis Meja) & 1 \\
\hline 4 & TAEKWONDO & 1 \\
\hline 5 & WUSHU & 1 \\
\hline 6 & FPTI (PANJAT TEBING) & 1 \\
\hline 7 & PELTI(TENIS LAPANGAN) & 2 \\
\hline 8 & MUAY THAI & 1 \\
\hline 9 & PERBASI (BASKET) & 2 \\
\hline 10 & PERCASI (CATUR) & 1 \\
\hline 11 & PERKEMI (KEMPO) & 1 \\
\hline 12 & POFI (PETANQUE) & 1 \\
\hline 13 & PSTI (TAKRAW) & 1 \\
\hline 14 & PERTINA (TINJU) & 1 \\
\hline 15 & PGSI (GULAT) & 1 \\
\hline 16 & PJSI (JUDO) & 1 \\
\hline 17 & POBSI (BILIAR) & 2 \\
\hline 18 & PODSI (DAYUNG) & 1 \\
\hline 19 & PERSEROSI (SEPATU RODA) & 1 \\
\hline 20 & KODRAT (TARUNG DERAJAT) & 1 \\
\hline 21 & FORKI (KARATE) & 1 \\
\hline 22 & GABSI (BRIDGE) & 1 \\
\hline 23 & IMI (MOTOR) & 2 \\
\hline
\end{tabular}




\begin{tabular}{lll}
\hline 24 & PAJI (ARUNG JERAM) & 1 \\
\hline 25 & ISSI (SEPEDA) & 1 \\
\hline 26 & IPSI (SILAT) & 1 \\
\hline 27 & PABBSI (ANGKAT BESI) & 1 \\
\hline 28 & PASI (Atletik) & 1 \\
\hline 29 & PBSI (Bulutangkis) & 3 \\
\hline 30 & PBVSI (Voli) & 3 \\
\hline 31 & PDBI (Drum Band) & 1 \\
\hline Jumlah & 42 \\
\hline
\end{tabular}

Dari tabel 1 dapat diketahui bahwa keberadaan lapangan olahraga semua cabang olahraga memiliki tempat atau lapangannya namun jumlah nya berbeda beda Dari hasil pengambilan data dengan lembar observasi maka dapat diketahui bahwa sarana olahraga sudah baik, hampir semua sarana dalam kategori kondisi baik dan dapat dilihat juga pada diagram berikut:

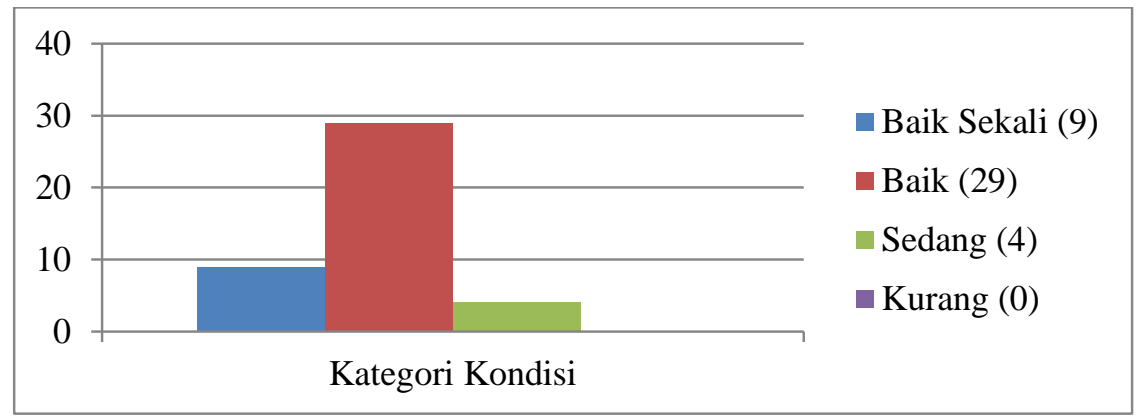

Gambar 1. Diagram Kategori Kondisi

Setelah diketahui jumlah dan kondisi sarana olahraga selanjutnya peneliti akan menganalisis status kepemilikan sarana olahraga. Ternyata status kepemilikan sarana peralatan pendidikan jasmani hasilnya berbeda-beda. Hasil stasus kepemilikan sarana dapat dilihat di gambar 2. Dari gambar 2 dapat diketahui bahwa sarana olahraga memiliki status kepemilikan berbeda beda, 33 sarana di miliki oleh pemerintah. Ada 9 sarana yang dimiliki swasta, dan tidak ada lapangan yang dimiliki pribadi. Berdasarkan tabel di atas dapat disimpulkan bahwa status kepemilikan dari 42 jenis sarana olahraga telah tersedia di Kota Jambi.

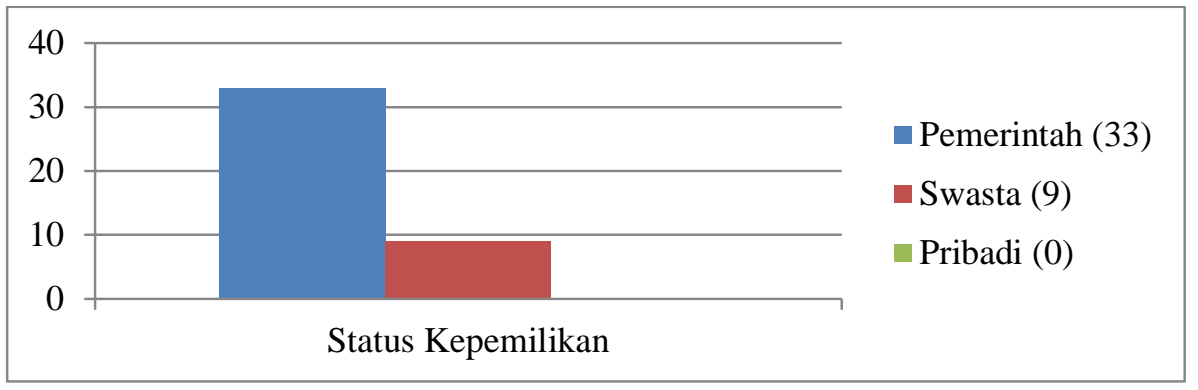

Gambar 2. Diagram Status Kepemilikan 


\section{SIMPULAN}

Berdasarkan analisis data yang telah dilakukan olah data dari penelitian Survei Kelayakan Sarana dan Prasarana pada 31 Cabang Olahraga Anggota Koni Kota Jambi Peserta Pekan Olahraga Provinsi Jambi Ke-23 Tahun 2020 dapat disimpulkan bahwa mengenai kelayakan sarana dan prasarana di Kota Jambi, dari 31 cabang olahraga yang ada di Kota jambi terdapat 42 sarana dan prasarana olahraga yang dapat digunakan dalam pelaksanaan Pekan Olahraga Provinsi yang ke 23 di Kota Jambi, 9 sarana dalam kategori baik sekali dengan persentase 21,4\%, 29 sarana dalam kategori baik dengan persentase 69\%, 4 sarana dalam kategori sedang dengan persentase 9,6\% dan tidak sarana dalam kategori kurang.

\section{DAFTAR PUSTAKA}

Anas, Sudijono. (2007). Pengantar Statistika Pendidikan. Jakarta: Grafindo Persada Raju.

Arikunto, Suharsimi. (2006). Prosedur Penelitian. PT Asdi Mahasatya: Jakarta

Clerici, M. (1976). Sport Facilities Problems and Plainning, Olimpics Solidarity: Tousame

Kemenpora. (2007). Undang-Undang Republik Indonesia Nomor 3 Tahun 2005 Tentang Sistem keolahragaan Nasional. Biro Humas Dan Hukum: Jakarta

Latuheru, John D. (1988). Media Pembelajaran Dalam Proses Belajar-Mengajar Masa Kini. Jakarta: Departemen Pendidikan dan Kebudayaan

Soekatamsi dan Srihati Waryati. (1996). Prasarana dan Sarana Olahraga. Surakarta: UNS Press

Soepartono. (1999). Sarana dan Prasarana Olahraga. Departemern Pendidikan dan Kebudayaan.

Sugiyono. (2006). Metode Penelitian Kuantitatif Kualitatif dan $R \& D$. Bandung: Alfabeta 